\title{
IARNA RUSEASCA. MATRIOȘKA ȘI REVOLUȚIA (1816-2017) Florian Olteanu
}

De 200 de ani, Rusia s-a aflat sub semnul revoluției. Majoritarea revoluțiilor rusești au început iarna. Vom vedea ce ne va rezerva viitorul. Toate aceste evenimente vor fi analizate în cartea Iarna Rusească. Matrioșka și Revoluția (1816-2017).

În acest an când se împlinesc 100 de ani de la izbucnirea Revoluției Ruse este un prilej să rememorăm în ce mod s-au desfășurat revoluțiile în Rusia, începând din 1816 încoace.

Analiştii vorbesc de Rusia ca de o matrioşkă, acea "păpuşă minune", din care ies alte păpuşi mai mici, care seamănă cu "mama". O incursiune în timp, arată că Rusia a evoluat, încă de la început, ca o forţă. Pe drumul "de la varegi la greci”, adică traseul care lega Marea Baltică de Constantinopol, s-au aşezat slavii. Slavi care au venit în contact cu nordicii, care le-au dat numele de „ruşi”. Multă vreme istoricii sovietici au dezbătut cele două teorii, „,normanistă” şi ,autohtonistă”. Adică slavii au avut totul, adică poporul şi elita politico-militară sau elita este de sorginte nordică? Un posibil răspuns poate fi dat de izvoare. Din cele două liste de delegaţii ruseşti la Constantinopolul bizatin, în secolul al $\mathrm{X}$-lea, marea majoritate a oficialilor aveau nume de sorginte nordică. Ştim că ruşii s-au creştinat în bloc, trecând Niprul, lăsându-l pe zeul războiului, în favoarea lui Iisus Hristos, cneazul Vladimir (termen nordic, o adaptare a numelui Valdemar) devenind "cel Sfânt", după cum şi Igor, din "Cântec despre oastea lui Igor" este o adaptare după numele nordic Ingvar.

Începuturile europene ale Rusiei sunt legate de oraşul Kiev, leagănul a ceea ce istoricii numesc „Rusia Kieveană”. usia a reuşit să se opună tătarilor, deşi iniţial plătise tribut "Hoardei de Aur", o rămăşiţă a defunctului Imperiu Mongol condus de Gingis Han. Mai târziu, a reuşit să lichideze centrul politic al acestora din Crimeea. După căderea Constantinopolului, la 1453, Rusia, al cărei centru politic devenise Moscova, şi-a asumat rolul de ,a treia Romă”, socotindu-se moştenitoarea de drept a Imperiului Bizantin.

Intrarea Rusiei în marea familie europeană se datorează acţiunilor lui Petru cel Mare, contemporan, între alţii cu Regele Ludovic XIV sau cu Dimitrie Cantemir, Constantin Brânco-veanu. $\mathrm{Cu}$ foarfeca în mână, Petru cel Mare, după câţiva ani de peregrinări în vestul Europei, s-a întors şi a făcut ordine prin veştmintele şi bărbile boierilor pravoslavnici. A întemeiat un alt oraş, Sankt Petersburg, pe Neva, arătând că pentru Rusia, ameninţarea venea dinspre nord. Apoi ar fi spus că "luăm de la Europa ce ne trebuie apoi îi întoarcem spatele". Aceste cuvinte, alături de enigmaticul "testament al lui Petru cel Mare" sunt corolarul politicii externe ruseşti din ultimele trei secole.

Şi românii au fost conştienţi că expansiunea Rusiei este o situaţie geopolitică de care trebuie profitat. A încercat, dar din păcate, total neinspirat, Dimitrie Cantemir, în 1711, acea diplomă de la Luţk, în cazul unui succes al ruşilor şi românilor echivalând cu o anexiune de catifea (printre altele, se prevedea că dacă neamul Cantemireștilor se stingea, Țarul şi boierii puteau decide pe cine să pună domn n.a.). Atunci ne-a salvat geniul militar al lui Carol al XII-lea Regele Suediei, fugit la Bender (Tighina în Transnistria de azi), pe care Petru îl bătuse la Poltava, în 1709.

Sub ţarul Petru al III-lea, soţul Ecaterinei cea Mare, Rusia, Austria şi Prusia s-au decis să facă ordine în Europa Centrală. În 1761, trupele ruseşti mărşăluiau pentru prima dată prin Berlinul "bătrânului Fritz", cum i se spunea lui Frederic II, regele Prusiei. Doar admiraţia ţarului pentru "regele filosof" 1 -a făcut săşi retragă trupele. Ecaterina cea Mare, nemţoaică de origine s-a lansat într-o puternică acţiune externă, în urma căreia harta Europei a fost remodelată. Astfel, va dispărea Polonia (împărţită de patru ori între Rusia, Prusia şi Austria), Moldova va pierde Bucovina în favoarea Austriei. Ea a avut ideea de a uni 
Moldova şi Ţara Românească sub numele de regatul Daciei (evident pregătind astfel anexiunea) şi restaurarea Imperiului Bizantin, proiect prezentat Austriei lui Iosif II sub numele de "proiectul grecesc" (eşuat prin ieşirea separată a Austriei, în 1791 din războiul ruso-austro-turc).

Ţarina Ecaterina cea Mare, continuatoare a politicii ţarului Petru cel Mare a încercat să pună în aplicare "proiectul grecesc", care viza restaurarea Imperiului Bizantin la Constantinopol şi Ţara Românească unită cu Moldova în Regatul Daciei, condus de un prinţ agreat de Austria şi de Rusia. Visul Rusiei de a avea ieşire la Marea Neagră s-a împlinit prin anexarea Crimeei, locuită de tătari (Crîmul pomenit de cronicarii moldoveni).

Un aspect esenţial în cadrul reformării scoietăţii rusești 1-a jucat relația cu Biserica Ortodoxă Rusă. Reforma Patriarhului Nikon din secolul al XVII-lea încercase să asigure o recuperare a decalajelor dintre Occident și Rusia, fără prea mare succes, însă.

Ţările Române, între 1768 şi 1812 vor fi teatru de război între austrieci, ruşi şi turci, în 1812, Basarabia intrând sub ocupaţie rusească, în contextul proiectatei campanii a lui Napoleon în Rusia. Atunci Rusia a reuşit, prin dragomanul Moruzi, la Hanul lui Manuc din Bucureşti să intercepteze scrisoarea prin care Napoleon informa Turcia că dorea să atace Rusia. Astfel se explică de ce Rusia a încheiat pace, la Bucureşti, în 1812, rapid „mulţumindu-se” doar cu Basarabia.

Rusia va încerca să dezmembreze Imperiul Otoman de mai multe ori. În 1814, adică acum mai bine de 200 de ani, la Odessa, Ioannis Capodistrias, un grec influent, sfetnic şi ministru de externe al Ţarului Alexandru a contribuit decisv la punerea bazelor "Eteriei" ("Frăţia"), o asociaţie greacă secretă, care urmărea obţinerea independenţei Greciei. În realitate, Rusia dorea să aprindă focul în Balcani, pentru a putea începe confruntarea cu otomanii.

Totuși, înfrângerea lui Napoleon prin retragerea și hărțuirea "Marii Armate" lăsase Rusia într-un dezastru economic și uman. Nemulțumirile populare față de funcționarea greoaie a structurii învechite a marelui imperiu al Rusiei își vor face simţită prezența. În decembrie 1816, în Rusia avea loc "răscoala decembriștilor", o revoltă a militarilor care a dorit reformarea Rusiei pe principii moderne. Deși a eșuat, "spiritul decembrist" a rămas ca un imbold la acțiune.

În Ţara Românească şi Moldova, erau de mai mult timp domni fanarioţi, unii dintre ei, precum Constantin Ipsilanti şi fiul său Alexandru Ipsilanti nutrind ambiţii de a deveni domni în Principate cu sprijin rusesc. Ruşii au căutat însă şi oameni ai locului, cum a fost necunoscutul „vătaf de plai” de la Cloşani, Tudor din Vladimirii Gorjului. Comandant al formaţiunilor militare de panduri, voluntari în armata rusă, Tudor Vladimirescu, un patriot şi un bun comandant era oficial "sudit" rus, adică se afla sub protecţia acestei puteri. Se pare că a redactat "Cererile norodului românesc", un prim proiect de constituţie, în casa consulului rus Pini din Bucureşti.

Rusia dorea astfel, ca prin acţiunea comună a celor doi, Ipsilanti şi Vladimirescu, să se aprindă scânteia. Lipsa de inspiraţie a lui Ipsilanti, care a demascat public Rusia a făcut ca ţarul, aflat la Laybach, la un congres al Sfintei Alianţe să dezavueze public mişcările. Ce a urmat, ştim. Revoluţia lui Tudor Vladimirescu a avut un succes efemer, el fiind lichidat de Ipsilanti, care şi el a trebuit să fugă în exil, după înfrângerile de la Drăgăşani şi Secu.

Totuşi, câştigul Revoluţiei a fost abandonarea sistemului fanariot şi trecerea la domni pământeni. Grecia şi-a câştigat independenţa în 1829, la tratatul de la Adrianopole, pe când pentru Principate începea oficial Protectoratul rusesc, inaugurat de facto, din 1774, după pacea de la Kuciuk Kainardji, când monopoul economic otoman asupra românilor era înlăturat.

Cei cinci ani de ocupaţie militară rusească, din 1829-1834 au fost ani în care Kiseleff, comandantul militar dorea să pregătească anexiunea. A fost dat atunci Regulamentul Organic, o constituţie, care deschidea perspectiva anexiunii Principatelor.

Din 1834 şi până în 1848, Principatele erau sub suzeranitate otomană şi protectorat ţarist. Rusia a fost ,jandarmul Europei”, prin implicarea ei în timpul Revoluţiei de la 1848, salvând Austria de la dezintegrare şi astfel, lăsând ordinea internaţională 
sigură. În 1853, Rusia dorea să preia moştenirea "omului bolnav", Imperiul Otoman, dar Franţa şi Anglia au înfrânt-o în Crimeea, pacea fiind semnată în 1856, când s-a decis, pe plan european, ca Principatele să se unească pentru a crea un stat tampon în calea expansiunii Ruse. Acum se consemnează o primă înfrângere geopolitică a Rusiei, pierderea sudului Basarabiei (5 000 de km pătraţi) care asigurau ieşirea sa la gurile Dunării.

Rusia, din dorinţa de a recupera terenul pierdut a fost de acord cu politica autoritară a domnitorului Alexandru Ioan Cuza. Ba chiar a încercat, după mai mulţi ani de la abdicarea acestuia, să tulbure apele la Bucureşti, să submineze poziţia Prinţului Carol, răspândind texte cu fotografia fiului cel mare al domnitorului, în care se spunea că Rusia i-a impus lui Cuza să facă reforma agrară. Rusia îşi va lua revanşa două decenii mai târziu, când la Congresul de Pace de la Berlin, în 1878, în urma războiului ruso-turc, la care a participat şi România, chemată în ajutor de Rusia (Războiul de Independenţă), a recunoscut independenţa României, i-a oferit Dobrogea, dar i-a luat sudul Basarabiei. Rusia a folosit mereu ideea că îi apără pe creștinii din Balcani, oprimați de Poarta Otomană.

Să mai spunem că ţarul s-a adresat direct locuitorilor României, când a intrat pe teritoriul ţării, ignorând autorităţile statului? Clasa politică românească a început să aibă puternice sentimente rusofobe, astfel explicându-se aderarea în secret la Tripla Alianţă, deşi Austro-Ungaria avea teritorii româneşti.

În primăvara anului 1881 , la 1/13 martie, Țarul Rusiei, Alexandru al II-lea a fost asasinat ca urmare a activității revoluționarilor ruși organizați în structura "Pământ și libertate". A doua zi, la 2/14 martie 1881, România se proclamă Regat, deoarece se estima că în Rusia vor fi tulburări. În cele din urmă situația s-a restabilit.

Până la răscoala din 1907, începuse pe teritoriul României o acţiune de vânzare de icoane ortodoxe ruseşti în care chipurile sfinţilor erau ale familiei Ţarului. "Iconarii", cum au fost numiţi, doreau să obţină de la ţăranii, pentru care Biserica era, de multe ori, singura sursă de cultură, adeziunea pen- tru Rusia. Orice acţiune critică la adresa AustroUngariei era văzută ca imixtiune a Rusiei. Orice politician din opoziţie care critica lipsa de acţiunea a guvernului faţă de românii din Transilvania, era taxat ca vândut Rusiei. Rusia a încercat să introducă dezbinare în România, prin acţiunile nihiliştilor şi socialiştilor expulzaţi.

În 1905, Rusia era zguduită de o nouă revoluție, ca urmare a nemulțumirii populare față de înfrângerea Flotei ruse de către japonezi la Tsushima. Atunci s-a resimțit, pentru prima dată necesitatea unor reforme, inclusiv a unei noi Constituții. Cel chemat să înfăptuiască reformele a fost, după câteva ezitări Piotr Stolîpin, numit Președinte al Consiliului de Miniștri în 1906. El era adeptul liniei dure de rezolvare a problemelor. Era un om al acțiunii, al faptelor, care nu se temea de moarte, în ciuda nenumăratelor atentate urzite contra sa de către sociasliști și anarhiști.

La 1/14 septembrie 1911, a fost asasinat primul ministru Piotr Stolîpin. Reformele sale care își propuseseră calmarea spiritelor agitate de socialiștii din Rusia, dar şi de către cei expulzați, ca Trotki, Vladimir Ilici Lenin puteau să schimbe cursul istoriei. Asasinarea lui Stolîpin, spre satisfacția lui Lenin a arătat că Rusia putea fi schimbată printro revoluție violenbtă. Intrarea Rusiei în priomul război mondial în 1914 a declanșat numărătoarea inversă, pe fondul măririi cheltuielilor militare, al salariilor mici, forțării muncitorilor și țăranilor să participe la efortul de război.

În 1914 însă, ţarul Nicolae II încearcă să atragă România, vizitând Constanţa. Prinţul moştenitor Ferdinand era căsătorit cu principesa Maria, pe jumătate englezoaică, pe jumătate rusoaică. După ce a început războiul, la doi ani, România intră în război de partea Antantei, deci a Rusiei, care recunoştea dreptul istoric asupra Basarabiei. Germania, profitând de nemulţumirile socialiştilor conduși de Kerenski, care iniţiaseră o revoluţie, văzând că socialiştii doresc continuarea războiului, îl aduc în secret pe Lenin, din exil (Churchill nota că fusese ascuns într-un vagon de tren sigilat ca "un bacil al ciumei”), care declanşează la 25 octombrie 1917 contrarevoluţia bolşevică. Scopul era atins, în 
martie 1918, Rusia făcând pace separată, la BrestLitovsk cu Puterile Centrale. Era a doua înfrângere geopolitică a Rusiei, întrucât ea nu a participat la Conferinţele de Pace de la Paris.

Stalin s-a opus "exportului de revoluţie", folosind până în 1945 ideea "comunismului într-o singură țară”. În 1919, România a oprit revoluția bolșevică din Ungaria condusă de Bela Kun. Rusia Sovietică (din 1922, URSS) s-a apropiat de Germania, unde, din 1933 venise la putere Adolf Hitler. URSS reuşise să normalizeze relaţiile cu toate statele, inclusiv cu România, dar chestiunea frontierei nu a fost niciodată rezolvată (unirea Basarabiei cu România nu fusese recunoscută oficial de către toate statele, rezolvarea chestiunii fiind lăsată în seama celor două state).

"Tătucul", Iosif Stalin fost Comisar al Poporului pentru Naţionalităţi, a creat o idee geopolitică deosebită: "enclavizarea". Dacă toate imperiile creau provincii în areale etnice delimitate, Stalin a fost deosebit, când a trasat frontierele republicilor unionale. A cuprins în fiecare dintre ele enclave locuite de etnici din republica vecină, rupţi de graniţă, dar care, la nevoie să ţipe după "ţara mamă". S-a văzut asta în Azerbaidjan cu Nagorno Karabach, s-a văzut în Cecenia, s-a văzut Transnistria (creată de Hitler, pentru Antonescu, dar păstrată de Stalin n.a.), în anii 90, s-a văzut în Georgia, cu ceva ani în urmă, se vede acum în Ucraina, prin anexarea Crimeii de către Federaţia Rusă.

În 1940 însă, după ce în 1939 semnase pactul Ribbentrop-Molotov, cu Germania, URSS, condusă de dictatorul Stalin, după ce ocupase jumătate din Polonia, ocupă Basarabia, Bucovina de Nord şi Ţinutul Herţa. Atacată de Germania, în 1941, URSS este în defensivă, cu inamicul la 25 de km de Moscova. Atunci Stalin a lăsat deoparte "ateismul" leninist şi a redefinit relația cu Patriarhia Rusă. Preoții și călugării, masi înainte oprimați, hăituiți, uciși chiar, au devenit aliați ai politicii oficiale a statului, rugându-se și chiar luptând contra ocupantului. Această măsură a lui Stalin a avut ecoul scontat în creșterea implicării țăranilor și muncitorilor la "marele război pentru apărarea patriei”. Stalin a permis și celorlalte culte să se exprime relativ liber, dar după război i-a pedepsit crunt pe musulmanii din Caucaz, acuzaţi că s-ar fi aliat cu inamicul german.

După Stalingrad însă, în 1943, URSS trece la contraofensivă şi, la 9 mai 1945, trupele sovietice mărşăluiesc prin jumătate din Europa, care devine aservită Moscovei, urmare a conferinţelor interaliate de la Teheran, Ialta, Postdam şi a Conferinţei de la Paris din 10 februarie 1947. Atunci, comuniştii români, aliaţi cu partidele istorice şi cu şeful armatei, Regele Mihai I 1-au arestat pe Ion Antonescu şi au acceptat încheierea armistiţiului, la 12 septembrie 1944. După abdicarea forţată a regelui, la 30 decembrie 1947, după ce acesta, în 1946 recunoscuse alegerile generale din noiembrie 1946, a urmat o luptă de poziţii între comuniştii naţionali şi cei aserviţi Moscovei, pentru a deţine puterea, luptă care a continuat şi în perioada cuprinsă între anii 1964, anul ,rupturii ideologice de URSS şi al aderării la calea chineză de cosntrucţie a socialismului” şi 1989, anul căderii regimului Ceauşescu.

Conştientizăm că şi România a fost pe lista lui Stalin. Deşi i-a tras de urechi pe "tovarăşii unguri" că "nu au avut 23 august" ca românii, le-a făcut cadou, după război, Regiunea Autonomă Maghiară, până la desfiinţarea regiunilor în 1968, adică exact zona unde se vrea ţinutul secuiesc această alcătuire pe care Lazlo Tokes o vede reală.

A mai fost un caz, prin 1908, în Bosnia Hertzegovina, o regiune cu sârbi, cu croaţi, cu musulmani, cu de toate, mai puţin cu individualitate şi legitimitate istorică. Ne îngrozim când ne amintim de "individualizarea" croaţilor de sârbi, un crunt război fratricid, e cam aşa cum s-ar individualiza oltenii de ardeleni, deşi în orice dicţionar se vorbeşte de limba sârbo-croată.

A urmat apoi Războiul Rece, o confruntare de poziţii sovieto-americană. În 1975, la Helsinki, ruşii au un nou succes diplomatic, obţinând recunoaşterea frontierelor de la finele războiului şi interzicerea dreptului de revizuire a acestora. Când Uniunea Europeană îşi realiza prin anii 50 primele strategii, cum îşi adună cloşca puii, "Maica Rusi" a reuşit să saboteze adoptarea proiectului Comunităţii Europene de Apărare, prin veto-ul Adunării Franceze din 1954 (mai are rost să amintim de cei circa 20 de 
milioane de comunişti din Franţa acelor ani?).

Ne mai miră de ce URSS a înfiinţat tratatul de la Varşovia abia în 1955 (NATO fusese înfiinţată prin 1949)? Adică dacă URSS a creat CAER în 1949, Occidentul a creat NATO. În anii 50, au apărut Comunităţile Europene, iar în 1955 Pactul de la Varşovia. "Crizele"din Occident sunt contempo-rane cu acelea din "monolitul Maicii Rusia": 1954-esecul CEA si criza Suezului vs Revoluţia din Ungaria; Criza scaunului gol -1967 (Franţa în dezacord cu Politica Agricolă Comună), răzbiul din Vietnam vs. Invazia din Cehoslovacia; Give our money back!- avertismentul adresat Comunității europenede Margareth Tatcher vs acutizarea situaţiei din Afganistan şi din ţările est-europene.

În 1991, după ce în 1989 căzuse Zidul Berlinului, se prăbuşea Uniunea Sovietică, Federația Rusă fiind principala moştenitoare. Era a treia înfrângere geopolitică a Rusiei. Totuşi, Boris Elţin, după retragere (nu înainte de a fi deschis larg porţile investiţiilor occidentale, corupţiei generalizate a sistemului politic şi energetic rusesc şi apariţiei marilor oligarhi) 1-a a dus pe Vladimir Putin.

Să fie oare semnul că Vladmir Putin se consideră moştenitorul Sfântului Vladimir? Acesta a reuşit să anihileze opoziţia oligarhilor (cam cum făcuse şi Petru cel Mare cu foarfeca sa celebră), a închis gura presei şi a pus în aplicare "Matrioşka lui Stalin". Adică, din pântecele "Matrioşkăi URSS" au ieşit micile păpuşi, republicile unionale. Dar dacă vreuna dintre ele vrea să se împrietenească cu o "păpuşă Barbie", imediat în pântecele ei apare o altă păpuşăenclavă care doreşte să se ducă spre "MatrioşkaRusia".

Astfel, invenţia lui Stalin dă roade, cu invenţiile cibernetico-geopolitice ale lui Vladimir Putin. Acesta are în mână doi aşi: o armată bine pregătită şi rusofoni dornici de a ,întoarce spatele Europei”, aşa cum dorea Petru cel Mare. Ce nu ştie multă lume, este că un jucător experimentat de poker, cum e Vladimir Putin, mai are aşi prin mânecă: Gazprom, Iranul, imposibilitatea americanilor de a construi ceva prin Irak, Afganistan, Egipt, războiul sângeros din Siria, conflictul israeliano-palestinian, incoerenţa politicilor Uniunii Europene de coeziune.

Deocamdată, Vladimir Putin a folosit dorinţa de anexare a Crimeei şi se aude că va încerca o soluţie similară cu Transnistria. Este semnalul că Rusia, încet, încet se trezeşte după a treia înfrângere geopolitică.

În ultimul an, tot mai multe regimuri care vor să redefinească raporturile internaționale cu Rusia au ajuns la putere în state ale Uniunii Europene, dar și în state NATO ca Turcia. Să nu uităm că Balcanii de Vest pot oricând să se alinieze geopolitic lângă Federația Rusă, și aici mă gândesc la FYROM și Serbia. Chiar dacă Muntenegru, Croaţia și Albania au intrat sub umbrela NATO, meciul în Balcanii de Vest se joacă puternic.

Caucazul este o zonă în care interesele SUA, UE și Federației Ruse se ciocnesc puternic, "afacerea gazoductelor" continuând să se deruleze.

Să nu uităm că Rusia joacă mereu, de sute de ani, aceeași carte a apărării creștinismului, a valorilor ortodoxiei, încercând să anatemizeze Uniunea Europeană, fără însă a înceta să aibă relaţii profitabile cu aceasta. Gazul rusesc este o "valută forte" acre închide ochii Uniunii Europene, mai ales când se apropie iarna și când se anunță scăderi extreme de temperatură. Federația Rusă a încercat să influențeze alegerile din Franța, cu siguranță că își va juca o carte mare și în alegerile de peste 10 zile din Germania 